\title{
Late unilateral breast enlargement after insertion of silicone gel implants: A histopathological study
}

\author{
Walter Peters PhD MD FRCSC ${ }^{1}$, Victor Fornasier MD FRCPC ${ }^{2}$
}

\begin{abstract}
W Peters, V Fornasier. Late unilateral breast enlargement after insertion of silicone gel implants: A histopathological study. Can J Plast Surg 2007;15(1):19-28.
\end{abstract}

Late unilateral breast enlargement after the insertion of silicone gel breast implants is a very rare phenomenon. The present study reports five women who presented with this finding over the past 20 years. Three of these patients presented with late unilateral hematomas, which developed nine, 12 and 14 years, respectively, after initial breast augmentation, in the absence of any known trauma. These patients presented for treatment one, four and 12 months, respectively, after their breast enlargements initially appeared. Two of these patients had developed chronic expanding hematomas. Extensive histopathological analyses of the capsules of all three patients provided explanations for the etiologies and progressions of the findings in these patients. In each of the three patients, the etiology of the hematoma was consistent with erosion of a capsular artery. Numerous large vessels were seen within the wall of the capsules. In each case, there was a class IV capsular contracture, which could have increased the friction of the intact implant against the capsule, and there was both old (hemosiderin deposits) and new bleeding into the pocket from the capsules. This supports the concept that numerous episodes of bleeding had occurred in each case. Histopathology also demonstrated the progression of the hematomas. After four weeks, only liquefied hematoma was present, while after four months, there were both liquefied hematoma and blood clotting. The hematoma on the surface of the capsule was becoming organized peripherally, but not centrally. After 12 months, the hematoma was becoming very well organized compared with the hematoma at four months. In one of the two remaining cases, late infection was the cause of the breast enlargement. Histopathology of this capsule showed that the involved capsule was six times as thick as the other side. It also showed edema and infiltration by scattered mononuclear cells, polymorphonuclear cells, and irregular crenated and degenerating nuclei. In the final patient, chronic inflammation appeared to be the cause of the breast enlargement. The histopathology of this capsule was unique. Its inner surface showed re-epithelialization and metaplasia of the ductal epithelium to form stratified squamous epithelium with early surface keratinization. These findings are consistent with synovial metaplasia. Several areas of the fibrous portion of the capsule showed patchy loss of cellular staining with loss of nuclei, indicative of necrosis. This produced a 'washed out' staining appearance. This tissue was paucivascular and fibrotic, and showed areas of fibrinoid necrosis, suggestive of mechanical abrasion and increased pressure.

\section{Hypertrophie mammaire unilatérale tardive après la pose d'une prothèse de silicone : examen histopathologique}

L'hypertrophie mammaire unilatérale tardive après la pose d'une prothèse de silicone est rarissime. Le présent rapport fait état de cinq femmes qui ont connu ce type de complication au cours des 20 dernières années. Chez trois d'entre elles, il s'agissait d'hématomes unilatéraux tardifs, qui sont apparus neuf, douze et quatorze ans, respectivement, après une plastie d'augmentation mammaire, en l'absence de tout signe apparent de traumatisme. Ces femmes ont consulté un médecin un, quatre et douze mois après l'apparition de l'hypertrophie et, dans deux cas, les hématome étaient en évolution chronique. Des examens histopathologiques approfondis des capsules prélevées chez les trois femmes ont fourni des explications quant à l'étiologie et à l'évolution de l'hypertrophie. Dans les trois cas, une érosion d'une artère capsulaire a été mise en cause dans l'apparition de l'hématome. De gros vaisseaux ont été observés en grand nombre dans la paroi des capsules. Dans chacun des cas, il y avait une rétraction capsulaire de classe IV, susceptible d'accroître le frottement de la prothèse intacte avec la capsule, ainsi que la présence de foyers hémorragiques récents et anciens (dépôts d'hémosidérine) dans la poche des capsules, ce qui laisse supposer la présence de nombreux épisodes de saignement. L'examen histopathologique a également révélé le caractère évolutif des hématomes. Au bout de quatre semaines, il n'y avait que des hématomes liquides, tandis que, au bout de quatre mois, il y avait présence de sang liquide et de sang coagulé. L'hématome, à la surface de la capsule, commençait à s'organiser à la périphérie, mais pas au centre. Au bout de douze mois, l'hématome commençait à être très bien organisé par rapport à l'hématome observé au bout de quatre mois. Dans un des deux autres cas, une infection tardive a été à l'origine de l'hypertrophie mammaire. L'examen histopathologique de la capsule touchée a montré que celle-ci était six fois plus épaisse que l'autre; en plus d'être œedématiée, elle présentait de l'infiltration par des cellules mononuclées, des granulocytes et des noyaux irréguliers, crénelés, en voie de dégénérescence, disséminés. Dans le tout dernier cas, une inflammation chronique a semblé être la cause de l'hypertrophie mammaire. L'examen histopathologique de la capsule a révélé un aspect singulier : la surface interne présentait des signes de réépithélisation et de métaplasie de l'épithélium canalaire, qui ont donné lieu à la formation d'un épithélium pavimenteux stratifié, accompagnée d'une kératinisation superficielle précoce. Il s'agit là d'éléments évocateurs d'une métaplasie synoviale. Plusieurs zones de la partie fibreuse de la capsule ont montré une coloration cellulaire lacunaire, avec perte de noyaux - indice révélateur de nécrose - ce qui a donné une coloration d'apparence " délavée ». Le tissu était paucivasculaire et fibreux et montrait des zones de nécrose fibrinoïde, aspect évocateur d'une abrasion mécanique et d'une augmentation de la pression.

Key Words: Enlargement; Silicone gel breast implants

${ }^{1}$ Division of Plastic Surgery; ${ }^{2}$ Department of Anatomic Pathology and Cytology, St Michael's Hospital, University of Toronto, Toronto, Ontario

Correspondence: Dr Walter Peters, Suite 802, 600 Sherbourne Street, Toronto, Ontario M4X 1W4. Telephone 416-926-7790,

fax 416-926-4997, e-mail walter.peters@utoronto.ca 
$\mathrm{L}$ ate breast enlargement after the insertion of silicone gel breast implants has been reported very infrequently in the literature $(1-8)$. The most common etiology of this finding appears to be late hematoma. No data exist on the incidence of hematoma in the late postoperative period. Most studies are in the form of individual case reports. Other causes of late breast enlargement are also uncommon, and include late infection (9-16), chronic inflammation $(17,18)$ and breast lymphoma (19).

The present study reports on five patients who presented with late unilateral breast enlargement after receiving silicone gel breast implants. The senior author has performed breast augmentation on over 3500 women. He has also explanted over 1000 silicone gel implants, mainly from 1992 to 1996, after the United States Food and Drug Administration- and Health Canada-imposed moratorium (20). The five patients in the present study are the only patients in his practice at the Wellesley Hospital, Toronto, Ontario in the past 20 years who have presented with late unilateral breast enlargement after the insertion of silicone gel breast implants.

\section{CASE PRESENTATIONS}

\section{Patient 1}

A 37-year-old woman presented nine years after her original breast augmentation; one month previously, she had experienced a sudden doubling of the size of her right breast with a very painful class IV capsular contracture (Figure 1).

She had originally undergone a bilateral submuscular breast augmentation using $220 \mathrm{~mL}$ Surgitek silicone gel breast implants (Medical Engineering Corporation, USA) nine years previously. Approximately one year postoperatively, she developed a class III contracture on the right side. At that time, she underwent a right unilateral open capsulectomy with insertion of a new $220 \mathrm{~mL}$ Surgitek silicone gel implant. Subsequently, her breasts remained soft (class I to II) for seven years. Approximately nine years after her original breast augmentation, she suddenly developed a painful class IV contracture of the right breast, with a doubling of its size (Figure 1).

At surgery, when the right capsule was opened, there was a sudden gush of a watery, brown fluid. This had the appearance of a liquefied hematoma. The implant was clinically intact. Clinical examination of the inner surface of the capsule showed what appeared to be 'granulation tissue'. A capsulectomy was performed.

Histopathology, using World Health Organization (WHO) stain (hematoxylin, phloxin, saffron and alcian green), showed that the capsule was lined by organizing hematoma (Figure 2). The cavity was lined by layered thrombus, which became progressively organized into fibrovascular granulation tissue toward the periphery of the capsule (Figure 2). Within the wall of the capsule, there was evidence of more recent bleeding (Figure 3). This suggested the presence of recurrent and continuing capsular bleeding. Figure 2 shows prominent engorged arteries. These are at risk of injury from any sharp edge of the intact implant, particularly when associated with a class IV contracture. Aerobic and anaerobic bacterial cultures and fungal cultures were negative. The patient made an uneventful postoperative recovery. Nine months later, she elected to have her left implant removed. She was subsequently free from any breast symptoms over a three-year follow-up period.

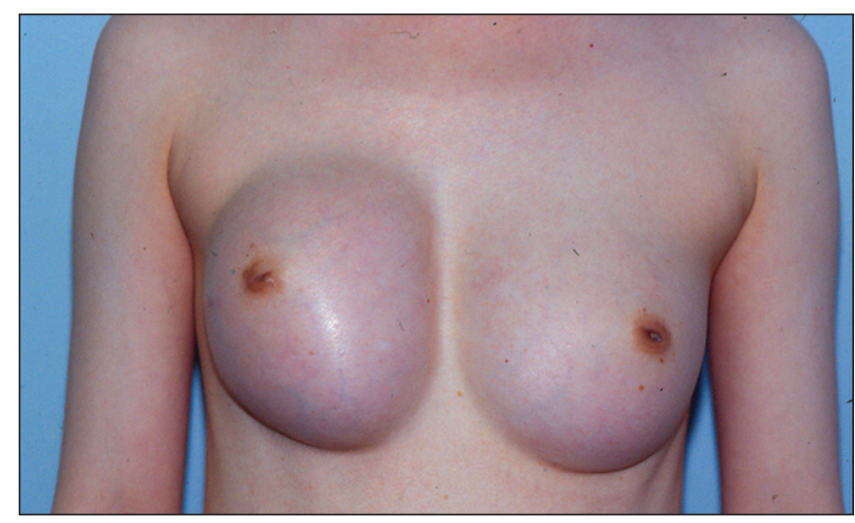

Figure 1) Patient 1: Appearance of patient nine years after breast augmentation with silicone gel implants. One month previously, she had experienced a sudden doubling of the size of her right breast and a very painful class IV capsular contracture

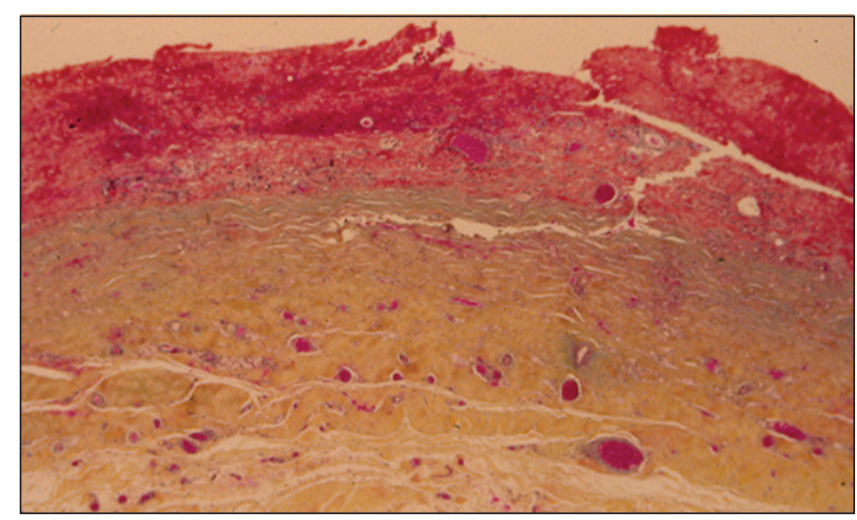

Figure 2) Patient 1: World Health Organization stain of the capsule surrounding the intact right implant. There was an extensive blood clot on the surface of the capsule. Bright red areas represent recent hematoma, and paler areas represent organizing hematoma. Within the capsule, there were several large, engorged vessels. One of these may have undergone erosion and bleeding, causing the development of hematoma (original magnification $\times 12.5$ )

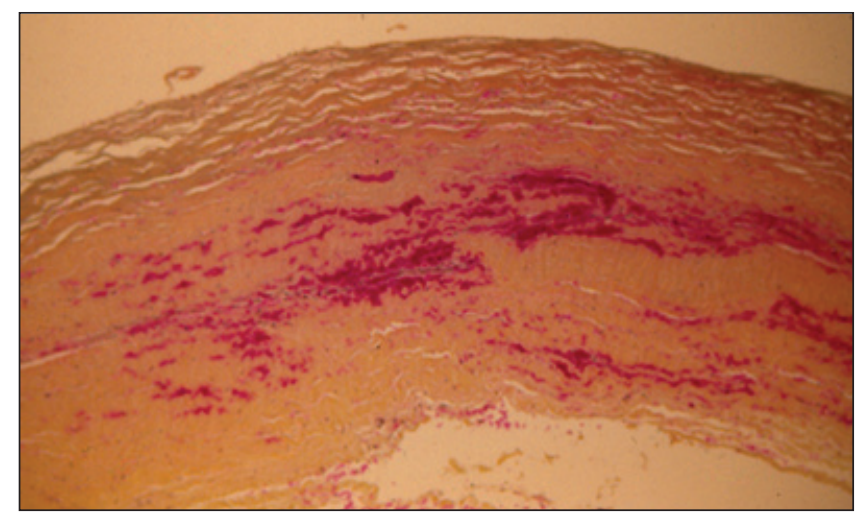

Figure 3) Patient 1: World Health Organization stain showing that, within the structure of the capsule, there were numerous areas of hemorrhage, indicating episodes of recurrent bleeding (original magnification $\times 50$ ) 


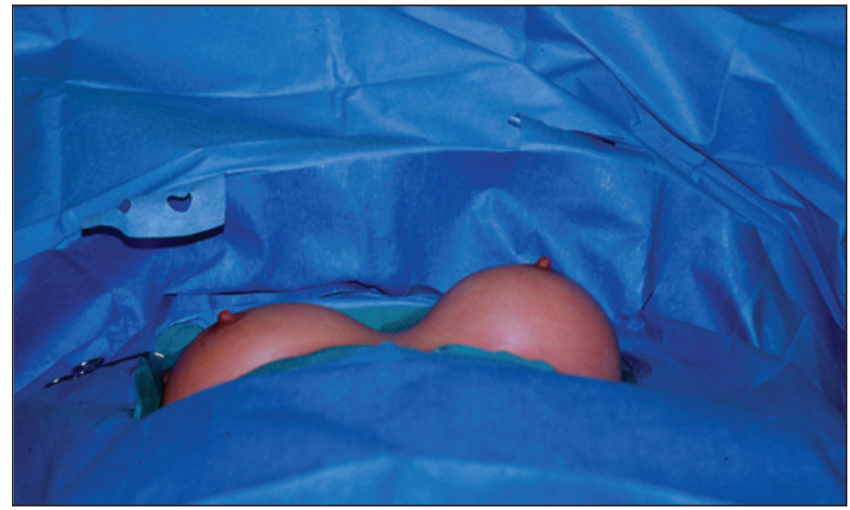

Figure 4) Patient 2: Appearance of patient 14 years after augmentation with silicone gel implants. She had developed a hematoma in the left breast four months earlier. The left breast had doubled in size compared with the right side. The left breast had a class IV contracture; the right had a class II contracture

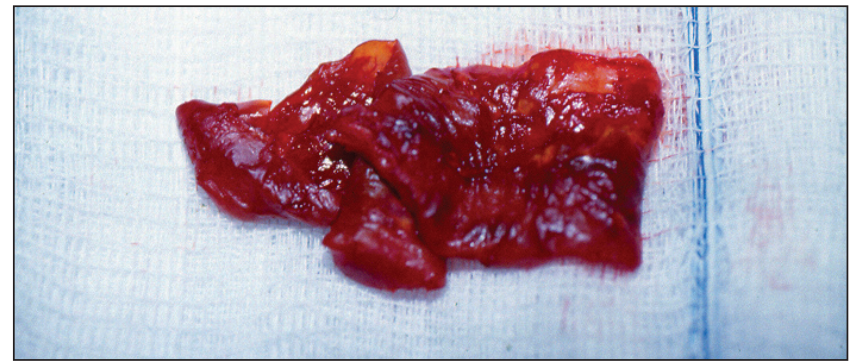

Figure 5) Patient 2: On opening the capsule, there was approximately $200 \mathrm{~mL}$ of a watery, brown fluid, as well as this blood clot

\section{Patient 2}

A 51-year-old woman presented 14 years after her original breast augmentation with a four-month history of significant enlargement of her left breast and a very painful class IV contracture (Figure 4).

She had originally undergone a bilateral submuscular breast augmentation 14 years previously. Surgitek silicone gel implants had been inserted, with a total volume $180 \mathrm{~mL}$. Approximately four years after her augmentation, she presented with a class III contracture on the left side. She underwent an open capsulectomy at that time, with insertion of a new $180 \mathrm{~mL}$ Surgitek implant. She remained symptom-free for the next 10 years. Then, 14 years after her original surgery, she presented with her current major unilateral enlargement and capsular contracture (Figure 4). Preoperatively, the patient requested that both of her implants be removed and that they not be replaced.

During exploration of the left breast, four months after her breast enlargement, approximately $200 \mathrm{~mL}$ of a watery, brown fluid was present. There was also a blood clot (Figure 5). Histopathology showed numerous areas of recent and organizing hematoma in the capsule (Figure 6). At the margins of the hematoma, there was organization into fibrovascular granulation tissue. On the external aspect of this, there were clusters of lymphocytes but no evidence of active inflammation (Figure 6). Sections of the blood clot showed early organization with fibrin networks, indicative of recent hemorrhage superimposed

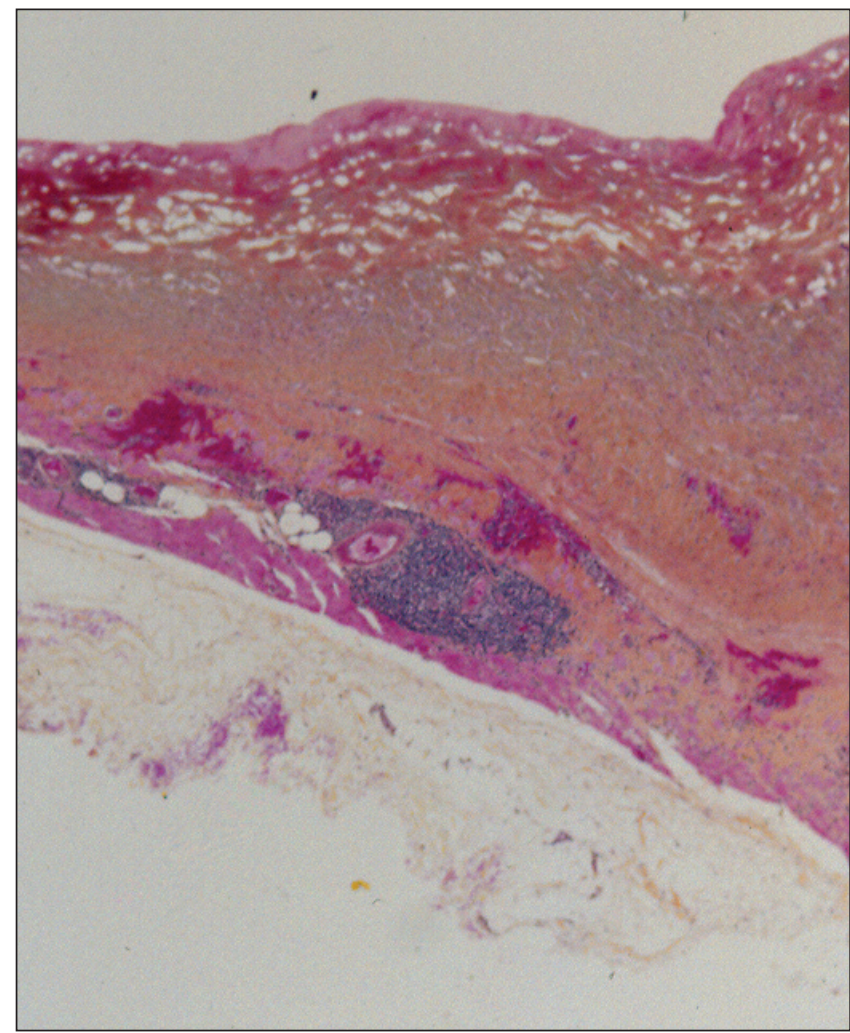

Figure 6) Patient 2: World Health Organization stain showing a layer of organizing hematoma on the inner surface of the capsule. This was superimposed on organizing fibrovascular granulation tissue. The outer capsule was composed of collagen with random orientation. On the other aspect of the capsule, there were small aggregates of lymphocytes and evidence of recent bleeding. Note the degree of organization of this hematoma capsule. At four months, it was much more advanced than the hematoma in patient 1 at one month (Figure 2) (original magnification $\times 12.5$ )

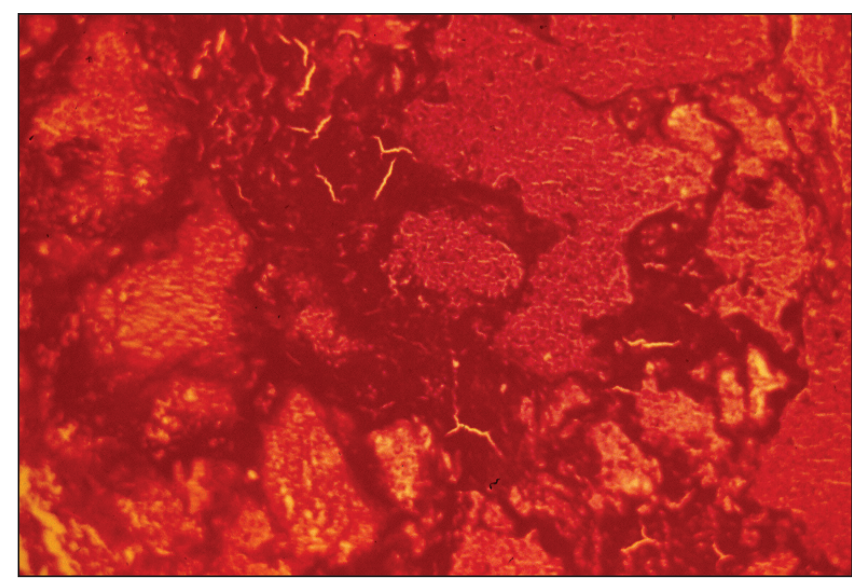

Figure 7) Patient 2: Hematoxylin and eosin staining of the capsule showing organizing hematoma from the solid blood clot shown in Figure 5. The fibrin lines that produced the darker areas indicate that this is early organization, indicative of recent bleeding (original magnification $\times 12.5$ )

on the organizing wall of the hematoma (Figure 7). Aerobic and anaerobic cultures showed coagulase-negative Staphylococcus species in broth cultures only. This was not 


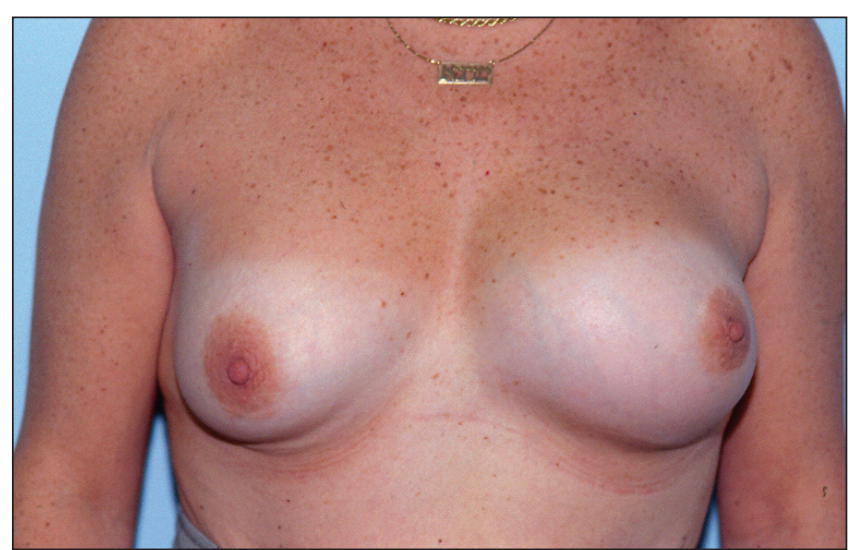

Figure 8) Patient 3: Appearance of a patient 12 years after breast augmentation with silicone gel breast implants. She presented with a oneyear history of progressive doubling of the breast size and development of a class IV capsular contracture. She had a class II result on the right side

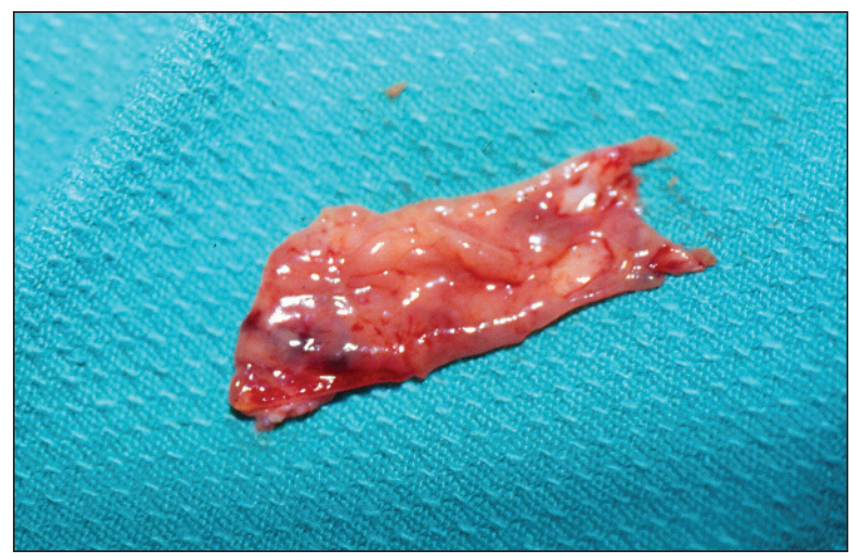

Figure 9) Patient 3: On opening the capsule, one year after the onset of the hematoma, there was a large volume of turbid, brown fluid as well as this blood clot

treated with antibiotics, because it likely represented an insignificant colonizing organism. Fungal cultures were negative. She had an uneventful postoperative recovery and remained symptom free over a three-year follow-up period.

\section{Patient 3}

A 51-year-old woman presented 12 years after her initial breast augmentation with a one-year history of progressive doubling of her left breast size and a painful class IV capsular contracture on that side (Figure 8).

She had received Surgitek silicone gel breast implants 12 years previously. She had a bilateral class II result for 12 years before her current symptoms developed. She requested bilateral removal of her implants.

During exploration of the pocket, a large volume of turbid, brown fluid was identified, together with a solid blood clot (Figure 9). Hematoxylin and eosin stain of the blood clot at one year (Figure 10) showed much greater organization than at four months (patient 2, Figure 7). The right implant was ruptured; the left implant had a small pinhole. The capsule on the right side was very thin. The capsule on the left side was thickened, with an outer fibrous layer and an inner layer of organizing fibrovascular hematoma (Figure 11).

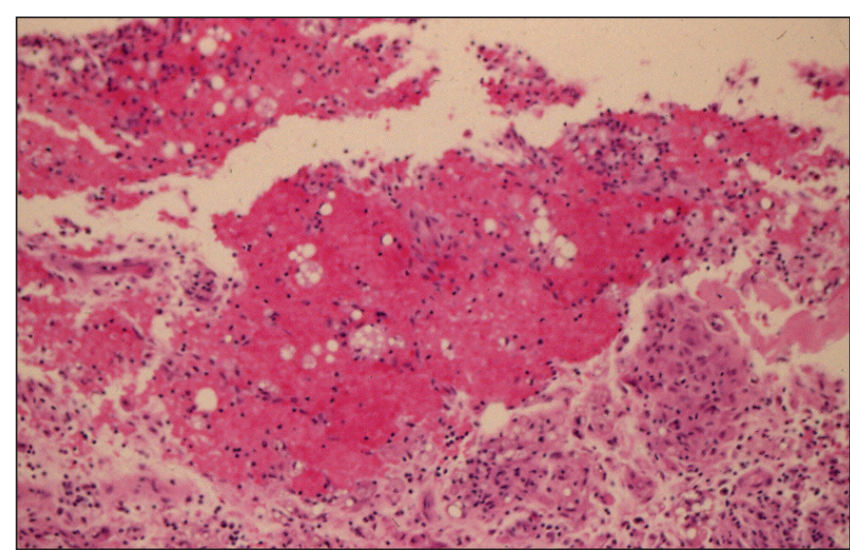

Figure 10) Patient 3: Hematoxylin and eosin stain of the hematoma on the surface of the capsule. After one year, the hematoma was becoming actively organized (compared with Figures 6 and 7). Very little collagenous tissue had formed in this organizing thrombus (original magnification $\times 100$ )

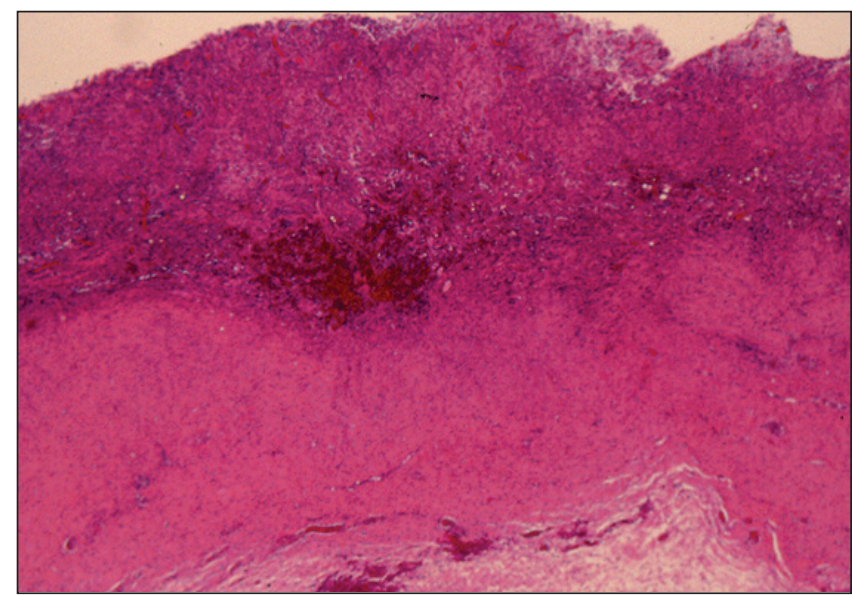

Figure 11) Patient 3: Hematoxylin and eosin stain of the capsule one year after the onset of the hematoma, showing extensive areas of chronic inflammation surrounding the areas of organizing hematoma (original magnification $\times 12.5$ )

Microscopically, the capsule showed evidence of an old hemorrhage (hemosiderin pigment) and a more recent organizing blood clot (Figure 11). The degree of organization of the hematoma at one year was much greater than that at four months (patient 2, Figure 6). On the outer aspect of the capsule in patient 3 , there were areas of chronic inflammation that were independent of the organization of the hemorrhage on the inner aspect of the capsule (Figure 11). Aerobic and anaerobic bacterial and fungal cultures were negative. After explantation, the patient remained symptom free over a three-year follow-up period.

\section{Patient 4}

A 29-year-old woman presented nine years after her initial breast augmentation with sudden, painful enlargement and distortion of her right breast.

Nine years previously, she had received bilateral, submuscular $250 \mathrm{~mL}$ Surgitek silicone gel breast implants. Following her surgery, she was lost to follow-up for six years. At six years, she had an excellent outcome with good symmetry and a bilateral 


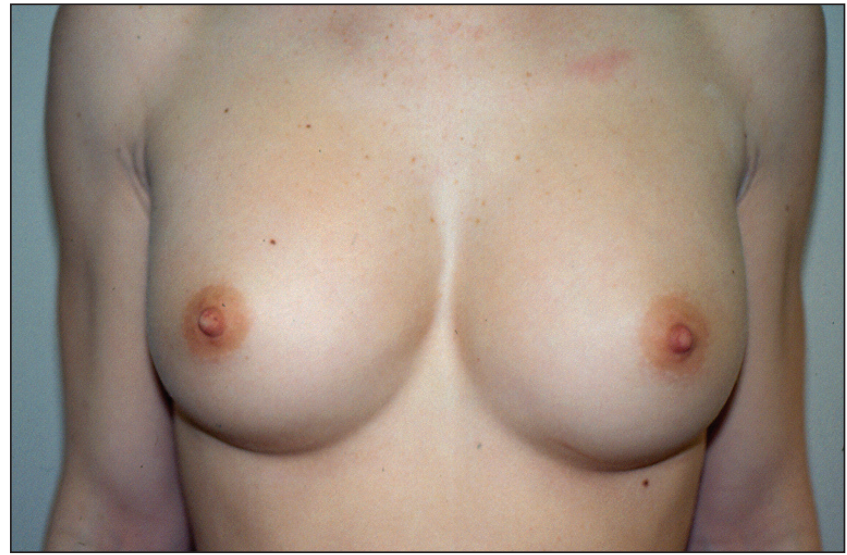

Figure 12) Patient 4: Appearance of patient six years after submuscular breast augmentation with silicone gel implants. The breasts are symmetrical with a bilateral class I result

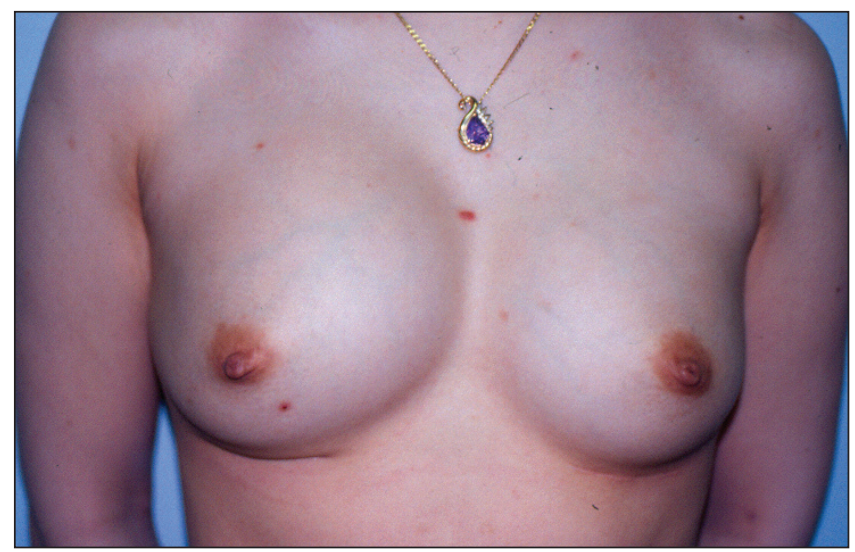

Figure 13) Patient 4: Appearance of the same patient, nine years after augmentation. The right breast had enlarged and become firmer and tender (class III contracture)

class I result (Figure 12). At that point, she wanted to obtain larger implants. However, she had other commitments that prevented surgery at that time.

She was next seen three years later, nine years after her initial breast augmentation. The right breast had suddenly enlarged significantly, and had become painful and tender (Figure 13). A booking was made for the right breast to be explored. However, she cancelled this booking because of other commitments. She presented six months later with further enlargement of her right breast and also with major distortion of the breast (Figure 14). Her right breast implant had shifted medially across the midline area. The breast had become more tender and painful with a class IV contracture.

During exploration of her right breast, it was found that the implant had ruptured. Clinically, there were extensive areas of granulation tissue on the surface of the capsule. A capsulectomy was performed. The left implant had also ruptured and was removed. The left breast had a smaller area of granulation material in the inferior aspect of the anterior capsule. This area was excised and sent for biopsy and cultures. Both pockets were thoroughly irrigated with bacitracin-saline solution. She was then started on intravenous clindamycin.

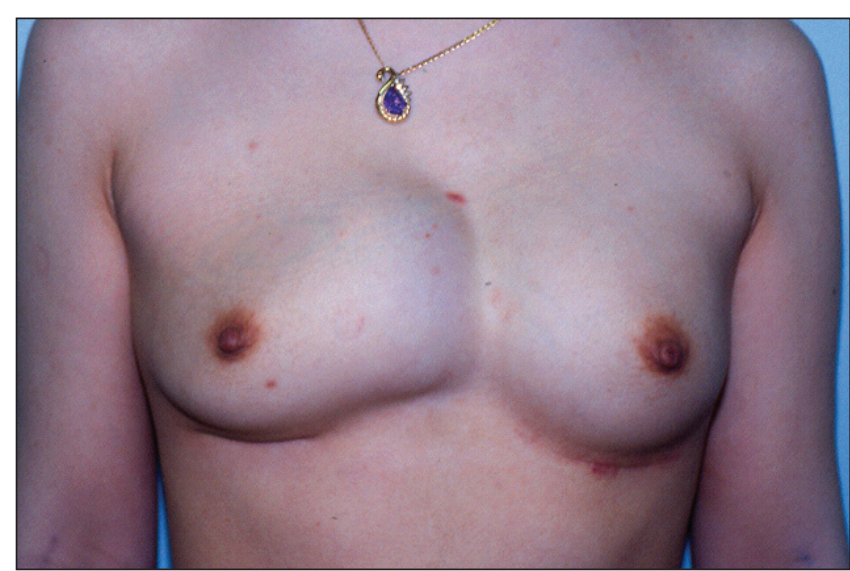

Figure 14) Patient 4: Appearance of the same patient 9.5 years after augmentation. The right side has developed a class IV capsular contracture, with shifting of the right implant across the midline

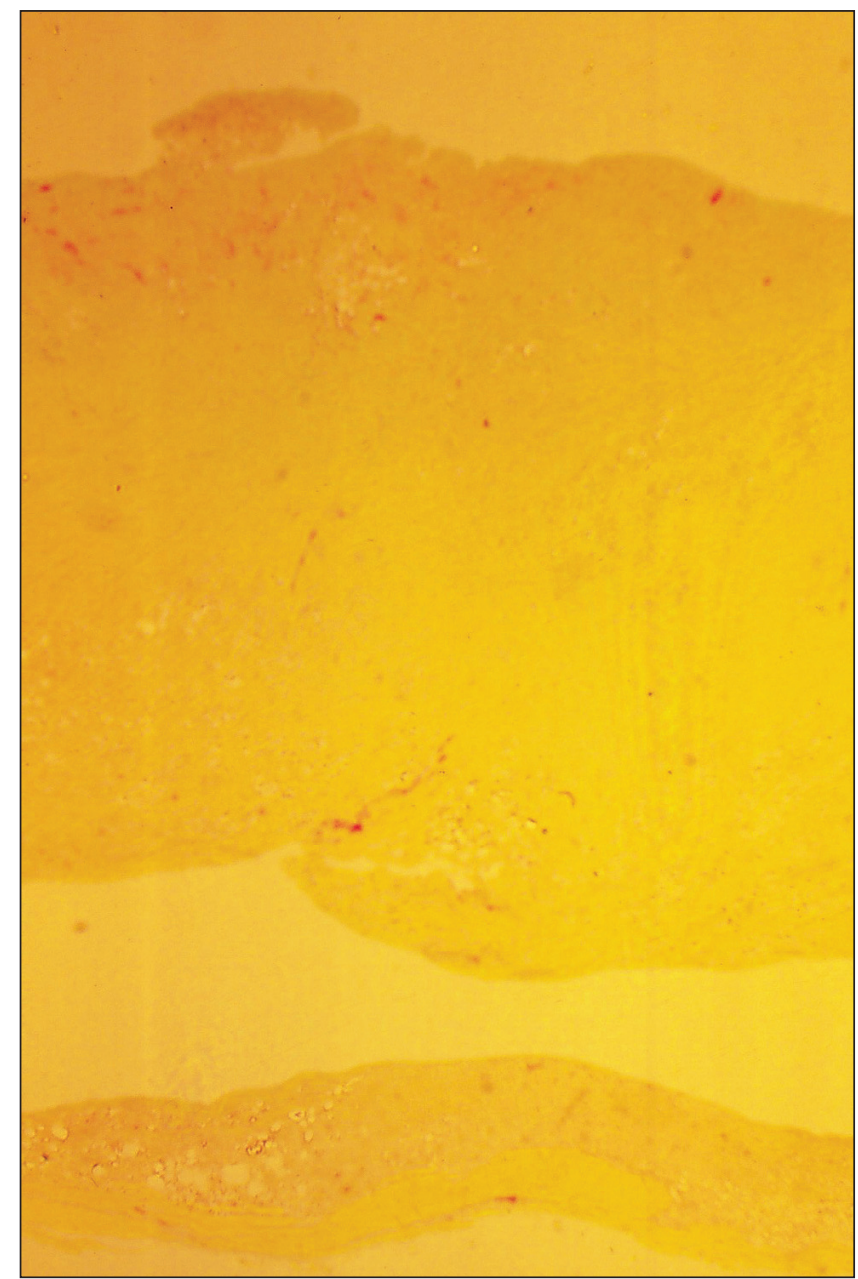

Figure 15) Patient 4: World Health Organization stain of the right breast capsule (top), showing that it was approximately six times the thickness of the left side (bottom) (original magnification $\times 25$ )

Histopathology (WHO stain) showed that the right breast capsule was six times as thick as the left side (Figure 15). The right capsule showed a mixed sprinkling of mononuclear cells 


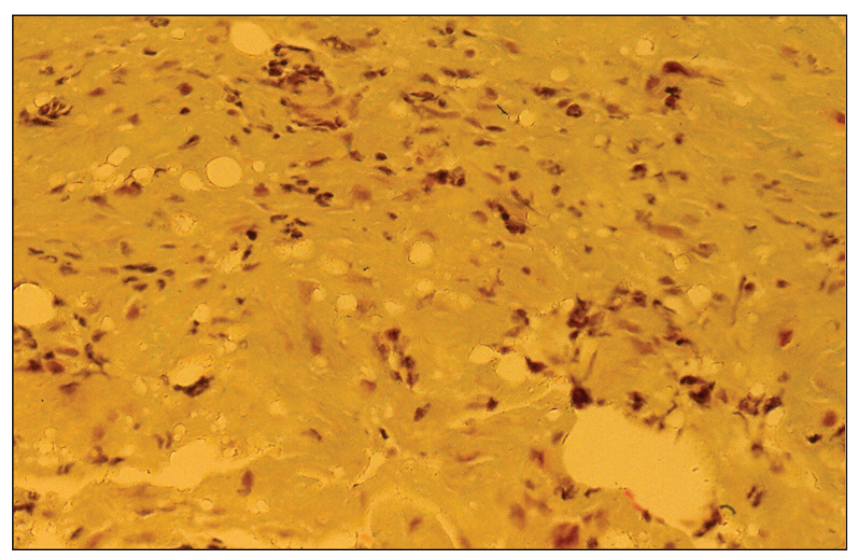

Figure 16) Patient 4: World Health Organization stain of the right capsule showing edema and infiltration by scattered mononuclear cells, polymorphonuclear cells, and irregular crenated and degenerating nuclei. This inflammatory infiltrate is consistent with a low-grade infection involving the capsule and implant pocket (original magnification $\times 250$ )

and polymorphonuclear cells, as well as cells with hyperchromatic crenated nuclei (Figure 16). This degree of cellular infiltration was highly suggestive of an infection in the breast pocket. Aerobic cultures from the capsule of the right breast demonstrated two strains of coagulase-negative Staphylococcus species. Anaerobic cultures showed a light growth of Bacillus species, which was resistant to penicillin, oxacillin, cefazolin and trimethoprim sulfa. Fungal cultures were negative.

On further questioning, she admitted that she had been an intravenous drug abuser for "a few years". In retrospect, she may have seeded her capsules from her intravenous drugs, either from contaminated injection fluid or from the skin surface.

\section{Patient 5}

A 37-year-old Russian physician presented with a one-year history of progressive enlargement, firmness and tenderness of her left breast, seven years after her initial breast augmentation (Figure 17). The left breast had increased in size by approximately 30\%. It had a class IV contracture.

She had originally undergone a bilateral subglandular breast augmentation in Moscow, Russia, using an unknown type of silicone gel implant. She had postoperative hematoma on the left side, which was ultimately drained. She rapidly developed bilateral class IV contractures. Four years after her original surgery, she underwent an open capsulotomy and removal of her implants in Berlin, Germany. No further information was available concerning treatment of the capsules. Bilateral Biocell gel implants (McGhan Medical Corporation, USA) were inserted in the subglandular plane. Two years later, she noticed progressive enlargement, firmness and tenderness of the left breast. The right breast had a class II result, and its size had not changed.

The left breast was explored. On opening the capsule, approximately $100 \mathrm{~mL}$ of a straw-colored fluid was expelled from the pocket under pressure. The capsular contracture had resulted in very tenacious adherence of the Biocell implant to her posterior capsule. When the Biocell implant was removed, a large portion of the posterior capsule was avulsed with and remained attached to the implant. A total capsulectomy was then performed, and samples were sent for histopathology and microbiology. Aerobic, anaerobic and fungal cultures showed

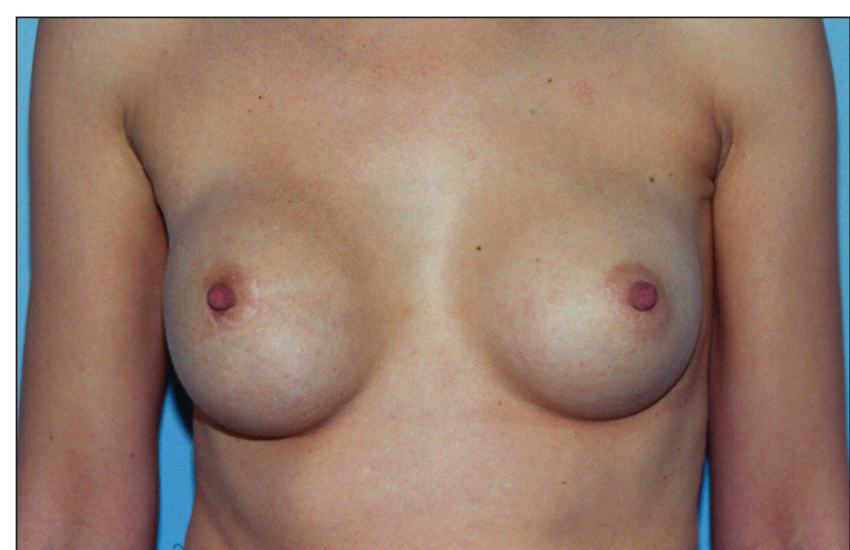

Figure 17) Patient 5: Appearance of patient seven years after breast augmentation with silicone gel implants and three years after replacement with Biocell (McGhan Medical Corporation, USA) implants. The left breast (class IV) is approximately 30\% larger than the right side (class II)

no evidence of growth. A new, smooth-walled Mentor silicone gel implant (Mentor Medical Systems Canada Inc) was inserted. She made an uneventful recovery. The right breast remained very soft and symmetrical with a class I result over a subsequent three-year follow-up.

Histopathological analysis (hematoxylin and eosin stain) showed that the capsule was a dense hyaline fibrous layer. The inner surface was covered by stratified squamous epithelium, showing early keratinization (Figure 18). This picture is consistent with synovial metaplasia. There were areas of transition from columnar epithelium to the stratified squamous epithelium, suggesting re-epithelialization from breast ductal epithelium (Figures 18 and 19). The squamous epithelium likely represented metaplasia of the ductal columnar epithelium, probably from the tissue reaction to interface activity between the capsule and the implant. In addition to the chronic inflammation within the capsule, there was evidence of hemosiderin pigment consistent with old hemorrhage (Figure 20). Some areas of the fibrous component of the capsule showed loss of nuclear definition in the collagen in a pattern that suggested necrosis (Figure 19). The eosinophilia of the collagen was indicative of fibrinoid necrosis. It seems possible that the pressure within the pocket may have contributed to the compaction of the capsular tissue and to the progression of the squamous metaplasia of the re-epithelialized inner surface of the capsule.

\section{DISCUSSION}

\section{Late hematoma}

In 1979, Georgiade et al (3) first reported late hematoma around a breast implant. It developed 2.5 years after breast augmentation with a saline-filled prosthesis containing $40 \mathrm{mg}$ of triamcinolone acetonide. At exploration, a medium-sized (1.0 $\mathrm{mm}$ external diameter) capsular artery was found to be eroded and actively bleeding. The authors suggested that the large dose of corticosteroid was responsible for this erosion.

Over the years, other authors have sporadically reported on late hematomas that had developed around various types of breast implants. In 1992, Marques et al (4) reported a case of a hematoma that developed three years after submuscular augmentation with smooth silicone gel implants. In 1996, Daw et al (5) reported on three patients who developed chronic 


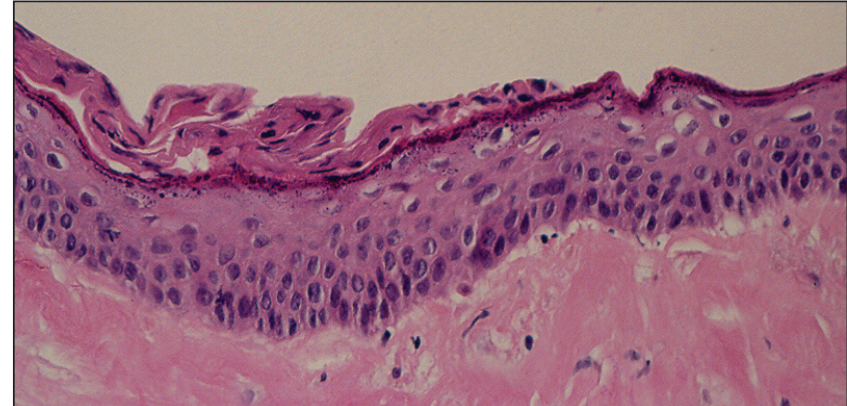

Figure 18) Patient 5: Hematoxylin and eosin stain of the surface of the left capsule showing a thickened layer of squamous epithelium with early keratinization along the surface. This represents synovial metaplasia. Deep to this epithelial layer, there was a well-developed area of hyalinizing fibrosis that had a paucity of cells (original magnification $\times 250$ )

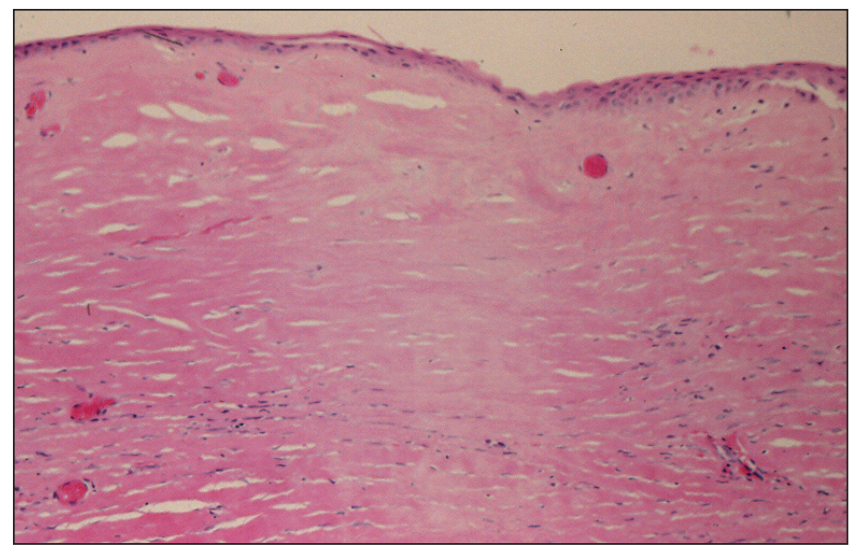

Figure 19) Patient 5: Hematoxylin and eosin stain of the left capsule showing patchy loss of cellular staining with loss of nuclei, indicative of necrosis. This produced a 'washed out' staining appearance. This tissue was paucivascular and fibrotic and the presence of fibrinoid necrosis of the collagen was suggestive of mechanical abrasion and increased pressure applied to the capsule from the pocket. This led to compression of vasculature and an anoxic state (original magnification $\times 100$ )

expanding hematomas six, seven and eight years, respectively, after receiving smooth silicone gel implants (5). In all of the patients, no specific evidence of erosion of a capsular artery was found. However, erosion of a capsular artery was thought to be the most likely cause of the hematomas.

In 1998, Wang et al (6) described two cases of late hematoma, which appeared six months and three years after breast reconstruction with polyurethane-covered silicone gel implants. These investigators believed that these hematomas were caused by the intense, highly vascular inflammatory response that was induced by the polyurethane coating. Both patients had undergone multiple capsulotomies and capsulectomies before receiving their polyurethane implants.

In 2005, Mauro et al (7) reported on a patient who developed late bilateral hematomas six months and 11 months after capsulectomy and secondary augmentation with textured silicone gel implants. Breakdown of an eroded capsular artery was also suspected; in this particular case, the authors suspected that the erosion was caused by friction between the rough surface of the textured prosthesis and the fibrous capsules. New capillary

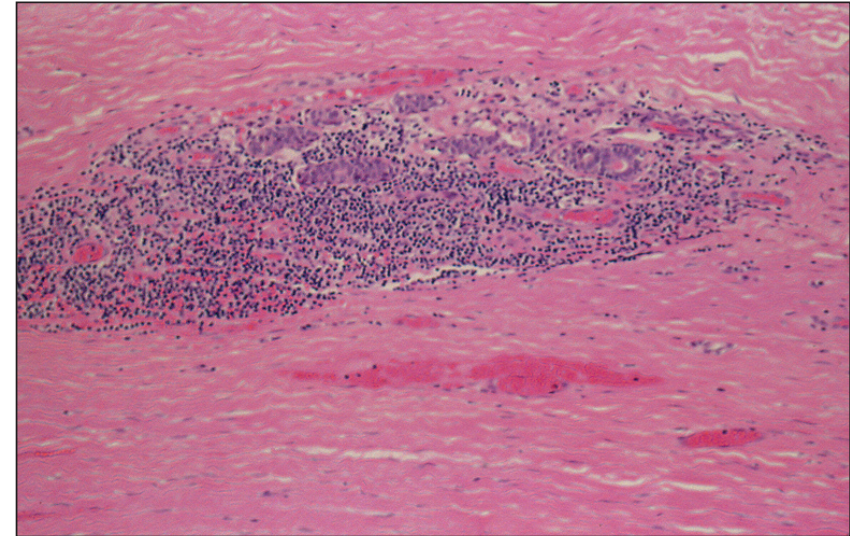

Figure 20) Patient 5: Hematoxylin and eosin stain of the left capsule, showing small aggregates of chronic inflammatory cells with evidence of hemosiderin-laden macrophages (original magnification $\times 100$ )

TABLE 1

Data for three patients with late hematomas

\begin{tabular}{lcc}
\hline Patient & $\begin{array}{c}\text { Time of onset of } \\
\text { hematoma after breast } \\
\text { augmentation, years }\end{array}$ & $\begin{array}{c}\text { Duration of } \\
\text { hematoma, months }\end{array}$ \\
\hline 1 & 9 & 1 \\
2 & 14 & 4 \\
3 & 12 & 12 \\
\hline
\end{tabular}

*The duration of the hematomas allowed an analysis of the progression of the hematomas over time

ingrowth on the inner surface of the capsule supported the theory that mechanical friction between the rough surface of the implant and the highly vascular capsule may have resulted in the hematomas. In 2005, Veiga et al (8) described a late hematoma that developed one year after insertion of subglandular, textured silicone gel implants. In this case, trauma was implicated. The patient was an obstetrics and gynecology resident who developed sudden breast pain and swelling after intense physical effort when assisting with a caesarean section in an obese woman. The trauma may have increased the mechanical friction between the rough, textured surface of the prosthesis and the highly vascular capsule, which may have led to the erosion and breakdown of a capsular artery.

After a review of the literature, the authors conclude that late hematoma can result from actual erosion of small- to medium-sized arteries in the breast capsule. This could develop from various causes, including normal wear and tear from friction of the implant against the capsule. Capsular contracture may be a factor in the development of such friction. Other possible causes include the force of capsular contracture against a 'knuckle' of an otherwise intact implant; friction between the capsule and the rough surface of a textured implant; an intense, highly vascular inflammatory response, particularly with polyurethane-coated implants; or trauma, which would increase existing friction between the implant and the capsule.

The histopathology of the present study provides an analysis of the pathophysiology and progression of the findings in the patients who developed late hematomas. Patients 1,2 and 3 developed unilateral hematomas nine, 14 and 12 years, respectively, after receiving silicone gel breast implants (Table 1). These patients presented for treatment one month, four 
months and one year after their breast enlargements initially appeared. There was no known trauma.

In the three patients with hematomas, the etiology of the hematomas would be consistent with erosion of a capsular artery. In each case, numerous large vessels were seen within the wall of the capsules (Figures 2, 6 and 11). The friction of the implants against the capsules could have eroded one of these vessels. This friction would be increased if there was significant capsular contracture. In addition, capsular contracture could cause a 'knuckle' in the wall of an implant, producing a 'sharp edge', which in itself could lead to vessel erosion. In these three patients, the implants were essentially intact, and there was class IV capsular contracture.

In each of the three cases of hematomas, histopathological examinations demonstrated the presence of both old (hemosiderin deposits) and new bleeding into the pockets from the capsules (Figures 2, 6 and 11). This finding supports the concept that numerous episodes of bleeding had occurred in each of these three cases.

In patient 1 , the hematoma had been present for only one month. The pocket was filled with brown fluid, representing liquefied hematoma. There was evidence of fresh bleeding with early organization on the inner aspect of the capsule (Figure 2). There was bright red blood and tan-coloured discolouration, indicative of hemosiderin within the capsule.

In patient 2 , the hematoma had been present for four months. The pocket was filled with approximately $200 \mathrm{~mL}$ of a watery, brown solution. However, clinically, there was also a large, well-organized, solid blood clot (Figure 5). Examination of the areas of hematoma on the surface of the capsule showed that it was becoming organized peripherally but not centrally (Figure 7). The organization of this hematoma at four months was much more advanced than the hematoma in patient 1 at one month (Figure 2).

In patient 3 , the hematoma had been present for one year. There were several areas of clinically well-organized hematoma (Figure 10). An hematoxylin and eosin stain of the hematoma on the surface of the capsule showed that it had become very well organized (compared with that of patient 2 at four months [Figure 6]). However, the collagen of the capsule was not organized into the compacted circumferential layers in the wall of the capsule (Figure 11).

In patients 2 and 3 of the current study, the increase in breast size was out of proportion to the size of the hematoma that was recovered. These two patients had their hematomas for four months and 12 months, respectively. The hematoma in these cases is regarded as a chronic expanding process. This progression of hematoma is well known, and has been extensively studied, particularly in the neurosurgical literature. The pathophysiology of this process has been described as a increase in osmotic pressure gradient, created by the breakdown of the hematoma and the resulting breakdown products (21). Labadie and Glover (22) proposed the currently accepted theory for the pathogenesis of expanding hematoma. They regarded the expansion to be related to the progressive inflammatory reaction stimulated by breakdown of the extravasated blood and to increased capillary permeability (23).

Labadie and Glover demonstrated that blood injected into the subcutaneous tissue of rats formed an expanding mass if a volume larger than $12 \mathrm{~mL}$ was used. The larger the amount of blood injected, the greater was the likelihood of subsequent progressive enlargement. The breakdown products of the hematoma induce a local inflammatory reaction, which increases the osmotic pressure gradient. The breakdown products also activate vasoactive substances that induce the formation of a delineating capsule surrounding the hematoma. Together, these features of local inflammatory reaction contribute to the progressive growth of the hematoma. In addition, they may stimulate neoangiogenesis within the capsule, increasing the risk of injury to blood vessels and the extravasation of blood into the pocket. Continued and new bleeding, and consequent inflammation, may also make capsular blood vessels more susceptible to injury. This creates a cycle of tissue damage, bleeding and inflammatory response that leads to chronic progressive enlargement. Histopathologically, there is a peripheral wall that progresses to become dense collagenous tissue (Figures 3 and 19).

\section{Late infection}

Infection after breast augmentation is uncommon. It is usually classified as early (within four weeks of augmentation) or late (from the second month onwards). The incidence of early infection after breast augmentation is thought to be $0.5 \%$ to $2 \%(9)$. Late infection is very rare and cases are largely anecdotal. Based on one long-term evaluation of over 50,000 implantations, the incidence of late implant infections was estimated to be approximately one in 10,000 (9).

Early infections are usually caused by endogenous bacteria, either from the skin or from the milk ducts. The responsible organisms include Staphylococcus aureus, Propionibacterium acnes, Staphylococcus epidermidis, Pseudomonas aeruginosa, betahemolytic Streptococcus species, Escherichia coli, other enteric bacteria and atypical mycobacteria. By contrast, the pathogenesis of late infections usually involves a bacteremia. This can be from a distant antecedent infection, or from an invasive medical or dental procedure, with seeding of the implant capsule or periprosthetic space. Late infections with $S$ aureus and Clostridium perfringens have been reported, manifesting a few days after extensive dental treatment $(9,10)$. A late implant infection with Enterococcus avium (previously known as group $Q$ streptococcus), has been described in a healthy woman 16 years after breast augmentation (11). It was speculated that this infection may have spread along milk ducts, or via hematogenous spread from an asymptomatic infection focus elsewhere, or from sexual intercourse. A late infection has also been reported with Klebsiella pneumoniae, developing after eight months (12). Fungal colonization with Candida albicans and Aspergillus niger has been documented in several late periprosthetic infections (13).

Late capsular contracture, presumably secondary to bacteremia with implant seeding, has also been postulated to occur in association with dental procedures (14), upper respiratory tract infections and urinary tract infections (15). Infection from other sources is also possible. The incidence of a transient bacteremia ranges from $5 \%$ for colonoscopy to $88 \%$ for periodontal surgery (16). This bacteremia could potentially result in a periprosthetic infection.

Capsular colonization is not necessarily related to the development of a periprosthetic infection. Netscher et al (24) identified a positive culture rate of $23.5 \%$ from capsules of 389 silicone gel implants, which were explanted from patients from 1992 to 1994, after the moratorium. In this study, there was a statistically significant correlation between positive capsule cultures and symptomatic capsular contrac- 
tures. During the same time period (1992 to 1995), Peters et al (25) analyzed capsular colonization in 100 consecutive patients who requested explantation. Forty-two per cent of the capsules demonstrated colonization by bacteria. The most common organisms cultured from colonization capsules were S epidermidis (28\%), other staphylococci (7\%), diphtheroids (6\%), streptococci $(3 \%)$, proprionobacter $(3 \%)$ and Enterococcus species (1\%). In this study, capsular contracture (class III and IV) was not related to capsular colonization $(\mathrm{P}>0.05)$. Other studies have shown that patients with systemic symptoms and capsular colonization can undergo a resolution of their symptoms after implant removal without capsulectomy (26).

In the current study, a 29-year-old woman (patient 4) presented nine years after a breast augmentation with a periprosthetic infection in her right breast, which rapidly progressed to a class IV capsular contracture with displacement of the implant across the midline (Figures 13 and 14, Table 2). Aerobic capsule cultures demonstrated two strains of coagulasenegative Staphylococcus species. Anaerobic cultures showed a light growth of Bacillus species, which was resistant to many antibiotics. That this patient had exposed herself to potential bacteremias through intravenous drug abuse strongly suggests that she may well have seeded her capsule from the hematogenous route. Bacteremia could have resulted from contaminated injected material or from endogenous staphylococci from the skin surface at the injection site.

\section{Chronic inflammation}

Patient 5 presented with a one-year history of progressive enlargement, firmness and tenderness of the left breast, seven years after her initial breast augmentation (Figure 17, Table 2). She had originally undergone a bilateral subglandular breast augmentation with smooth silicone gel breast implants, seven years earlier in Moscow. She developed a hematoma on the left side, which was drained. She subsequently developed a left unilateral class IV capsular contracture. Four years after her original surgery, she underwent a bilateral open capsulectomy and insertion of bilateral subglandular Biocell silicone gel implants. Two years later, she noticed progressive enlargement, firmness and tenderness of the left breast (Figure 17).

During exploration of the left breast, approximately $100 \mathrm{~mL}$ of a straw-coloured fluid was expelled from the pocket under pressure. Intracapsular fluid, which is frequently seen on radiological assessment, has been shown to be more common with textured surface implants, such as the current Biocell implants (27). This fluid may result from friction of the textured implant surface against the capsule.

The McGhan Medical Corporation developed Biocell textured implants in the late 1980s. The Biocell surface is an aggressive, open-pore, textured surface, created with a lost-salt technique (28). The elastomeric shell is placed on a bed of finely graded salt, and light pressure is applied to increase the depth of the depressions. A mirror image of the salt surface is impregnated onto the elastomeric surface.

Usually, tissue ingrowth into the surface of a Biocell implant is minimal. However, if there is significant capsular contracture (as in patient 5), then tissue ingrowth is increased. In patient 5 , the posterior breast capsule was very tenaciously adherent to the implant surface. This resulted in avulsion of much of the posterior capsule when the implant was removed. The aggressive class IV capsular contracture in patient 5 may
TABLE 2

Data for the two patients with late infection and chronic inflammation

\begin{tabular}{lcc}
\hline Patient & $\begin{array}{c}\text { Time of onset of breast } \\
\text { enlargement after breast } \\
\text { augmentation, years }\end{array}$ & Etiology \\
\hline 4 & 9 & Infection \\
5 & 7 & Chronic inflammation \\
\hline
\end{tabular}

have resulted if her original capsule was not removed before the Biocell implants were inserted.

Patient 5 is of particular interest because of the re-epithelialization on the inner aspect of the capsule. This is well demonstrated in the hematoxylin and eosin-stained sections (Figures 18 and 19). The presence of early surface keratinization (Figure 18) is regarded as a metaplastic response to re-epithelialization. The re-epithelialization is regarded as ingrowth of ductal epithelium along the inner surface of the capsule, undergoing metaplasia to squamous epithelium. This may be a function of the length of duration of the implant in situ, the class IV contracture of the capsule, the history of previously recognized and drained hematoma, her history of previous capsulotomy and removal of original implants, and subsequent reimplantation of new implants. Re-epithelialization along the inner surface of the capsule has been recognized in both textured and smooth-walled gel and saline implants (17). Ko et al (18) have suggested that the development of squamous metaplasia is a dynamic process, and is an ongoing transitional histological finding in the development and progression of the implant-capsule interface. It has also been suggested that in the early development of the capsule, there is a 'worn away' form that occurs over time as a result of friction and shearing forces caused by implant movement relative to the enveloping capsule.

The current study sheds further light onto the etiology and pathogenesis of late unilateral breast enlargement after insertion of silicone gel breast implants. The extensive histopathological findings in these five patients demonstrate significant and unique findings concerning the etiology and pathogenesis of enlargement caused by late hematoma, infection and inflammation.

ACKNOWLEDGEMENTS: The present study was funded by a grant from the Medical Research Council of Canada and a grant from the Plastic Educational Foundation of the American Society of Plastic and Reconstructive Surgeons.

\section{REFERENCES}

1. Biggs TM, Cukier J, Worthing JF. Augmentation mammaplasty: A review of 18 years. Plast Reconstr Surg 1982;69:445-52.

2. Little G, Baker JL Jr. Results of closed compression capsulotomy for treatment of contracted breast implant capsules. Plast Reconstr Surg 1980;655:30-3.

3. Georgiade NG, Serafin D, Barwick W. Late development of hematoma around a breast implant, necessitating removal. Plast Reconstr Surg 1979;64:708-10.

4. Marques AF, Brenda E, Saldiva PH, Andrews JM. Capsular hematoma as a late complication in breast reconstruction with silicone gel prostheses. Plast Reconstr Surg 1992;89:543-5.

5. Daw JL, Lewis VL, Smith JW. Chronic expanding hematoma within a periprosthetic breast capsule. Plast Reconstr Surg 1996;97:1469-72.

6. Wang BH, Chang BW, Sargeant R, Manson PN. Late capsular hematoma after breast reconstruction with polyurethane-covered implants. Plast Reconstr Surg 1998;102:450-2. 
7. Mauro S, Eugenio F, Roberto B. Late recurrent capsular hematoma after augmentation mammaplasty: Case report. Aesthetic Plast Surg 2005;29:10-2.

8. Veiga DF, Filho JV, Schnaider CS, Archangelo I Jr. Late hematoma after aesthetic breast augmentation with textured silicone prosthesis: A case report. Aesthetic Plast Surg 2005;29:431-3.

9. Brand KG. Infection of mammary prostheses: A survey and the question of prevention. Ann Plast Surg 1993;30:289-95.

10. Hunter JG, Padilla M, Cooper-Vastola S. Late Clostridium perfringens breast implant infection after dental treatment. Ann Plast Surg 1996;36:309-12.

11. Ablaza VJ, LaTrenta GS. Late infection of a breast prosthesis with Enterococcus avium. Plast Reconstr Surg 1998;102:227-30.

12. Bernardi C, Saccomanno F. Late Klebsiella pneumoniae infection following breast augmentation: Case report. Aesthetic Plast Surg 1998;22:222-4.

13. Williams K, Walton RL, Bunkins J. Aspergillus colonization associated with bilateral silicone mammary implants. Plast Reconstr Surg 1983;71:260-1.

14. Ellenbogen R. Breast implant encapsulation in association with dental work. Plast Reconstr Surg 1986;78:541. (Lett)

15. Rigg BM. Breast encapsulation following a minor distant infection. Plast Reconstr Surg 1987;79:505. (Lett)

16. Durack DT. Prophylaxis of infective endocarditis. In: Mandell GL, Bennett JE, Dolin R, eds. Principles and Practice of Infectious Diseases, 4th edn. New York: Churchill Livingstone, 1995:793-9.

17. Raso DS, Crymes LW, Metcalf JS. Histological assessment of fifty breast capsules from smooth and textured augmentation and reconstruction mammoplasty prostheses with emphasis on the role of synovial metaplasia. Mod Pathol 1994;7:310-6.

18. Ko CY, Ahn CY, Ko J, Chopra W, Shaw WW. Capsular synovial metaplasia as a common response to both textured and smooth implants. Plast Reconstr Surg 1996;97:1427-33.
19. Gaudet G, Friedberg JW, Weng A, Pinkus GS, Freedman AS. Breast lymphoma associated with breast implants: Two case-reports and a review of the literature. Leuk Lymphoma 2002;43:115-9

20. Bondurant S, Ernster V, Herdman R, eds. Safety of Silicone Breast Implants, 2000, Institute of Medicine. Washington, DC: National Academy Press.

21. Friedlander HL, Bump RG. Chronic expanding hematoma of the calf. A case report. J Bone Joint Surg Am 1968;50:1237-41.

22. Labadie EL, Glover D. Physiopathogenesis of subdural hematomas, Part 1: Histological and biochemical comparisons of subcutaneous hematoma in rats with subdural hematoma in man. J Neurosurg 1976;45:382-92.

23. Reid JD, Kommareddi S, Lankerani M, Park MC. Chronic expanding hematomas: A clinicopathologic entity. JAMA 1980;244:2441-2.

24. Netscher DT, Weizer G, Wigoda P, Walker LE, Thornby J, Bowen D. Clinical relevance of positive breast periprosthetic cultures without overt infection. Plast Reconstr Surg 1995;96:1125-9.

25. Peters W, Smith D, Fornasier V, Lugowski S, Ibanez D. An outcome analysis of 100 women after explantation of silicone gel breast implants. Ann Plast Surg 1997;39:9-19.

26. Dowden RV. Periprosthetic bacteria and the breast implant patient with systemic symptoms. Plast Reconstr Surg 1994;94:300-5.

27. Ahn CY, Ko CY, Wagar EA, Wong RS, Shaw WW. Clinical significance of intracapsular fluid in patients' breast implants. Ann Plast Surg 1995;35:455-7.

28. Danino AM, Basmacioglu P, Saito S, et al. Comparison of the capsular response to the Biocell RTV and Mentor 1600 Siltex breast implant surface texturing: A scanning electron microscopic study. Plast Reconstr Surg 2001;108:2047-52. 